needles, preferably ordinary sewing needles or curved intestinal needles. Accuracy in suturing is, of course, indispensable, but it is equally important to get a good hold on the skin flap, so that the stitches will not cut out when they are moistened with urine. As regards dressings, strips of moist boric lint wrapped round the organ and changed as often as they are soiled with urine are probably the most satisfactory, and are certainly the most comfortable for the patient. I have not found any particular advantage in keeping a catheter tied in to prevent the passage of urine over the wound. An instrument tends to set up urethritis and to keep a certain amount of tension on the stitches; furthermore, it does not always succeed in keeping the wound dry, as urine is apt to leak by the side of it.

The operation can be performed at any time after the age of 3 , but it is certainly easier when the boy is older, as the parts are larger and simpler to handle. In the cases which I have completed the results are extremely satisfactory. The urine is passed freely and projected forwards in a satisfactory stream, the straightness of the organ being all that could be desired. The new lining of the urethra, as seen in those cases in which a fistulous opening formed, seems to have taken on the character of mucous membrane. I have now operated on five cases; two are completely healed, one has a fistulous opening which remains to be closed, and in two the third stage has not yet been attempted; in all, however, the straightness of the organ is entirely satisfactory.

Queen Anne-street, W.

\section{ON A CASE OF ADDISON'S DISEASE IN A BOY AGED TEN YEARS. ${ }^{1}$}

\section{BY FREDERICK LANGMEAD, M.D. LOND.,} M.R.C.P. LOND.,

ASSISTANT PHYSICIAT TO THE ROYAT FREE HOSPITAL; THE HOSPITAY FOR SICK CHILDREN, GREAT ORMOND STREE' ; AND THE SEAMEN'S HOSPITAL SOCIETY (DREADYOUGHT), GREEYWICH.

DEFINITE cases of Addison's disease in children are without doubt very rare. In the annals of the Hospital for Sick Children, Great Ormond-street, no record appears of a post-mortem examination on a patient who had been the subject of this disease, nor is there any clinical record of a case in which the symptoms were convincing enough to make the diagnosis more than questionable. Comby has collected 21 cases in children, and Dezirot 48 cases in children under 16 . Of these, only 6 were under 10, the majority being in the eleventh and fifteenth years of life. Osler records an example of the disease occurring congenitally. Monti was able to find records of 11 cases in children from 3 to 14 years old. The disease in children would appear to produce symptoms very similar to those occurring in adults. Although protracted cases are described, a greater proportion run a very acute course in children. Apparently the pigmentation is nsually less obvious than in the majority of adult cases, although, as is well known, a few of the latter show little or no darkening of the skin or mucous membrane. Death from convulsions and coma would appear also to be relatively more frequent in children and death from asthenia relatively less. According to Gerhardt convulsions are seen in twofifths of the cases in children. Netter describes a case in a child, aged 4 years, who was suddenly taken ill with vomiting, diarrhœea, and depression, and died in three days.

The following case has many interesting features. The patient, a boy aged 10, was admitted to the Royal Free Hospital on Sept. 17th, 1912, at 6 A. Ir., and died four hours after admission. On the evening before, vomiting had started abruptly, accompanied by restlessness, and followed by loss of consciousness. On admission he was seen to be unconscious, the elbows, wrists, and knees being rigidly flexed, and the fingers extended. The temperature was subnormal and the pulse rapid and weak. The abdomen was retracted. The knee-jerks were present, and the plantar response was flexor. Frequent convulsive seizures occurred until death.

The case gave rise to much conjecture as to its nature,

1 The specimen was shown at the Medical Society of London on Jan. 27 th, 1913.
J and remained undiagnosed until the post-mortem examination. A possible explanation appeared to be meningitis, but the rapidity of its course was against this view. Moreover, the optic dises were normal, and cerebro-spinal fluid withdrawn by lumbar puncture showed no abnormality beyond absence of reducing power. The possibility of uræmia was excluded by the fact that a catheter specimen of urine was normal. Acetone was not present, an observation which excluded "cyclical vomiting" from the diagnosis. The pigmentation amounted to no more than a slight diffuse brownness of the skin, including that of the abdomen, and would not give rise to comment in a child of the poor at the end of the summer. Later it was learnt by careful questioning of the mother that the pigmentation had been noticed to have gradually deepened for about 12 months, and that the boy had been subject to attacks of diarrhoea for "several months," and had been slowly getting weaker. The boy's father had died from phthisis ten years before, and two aunts and one uncle of his mother also clied from the same disease.

Necropsy. - The body was that of a somewhat wasted boy, the skin showing slight general pigmentation without maculæ.

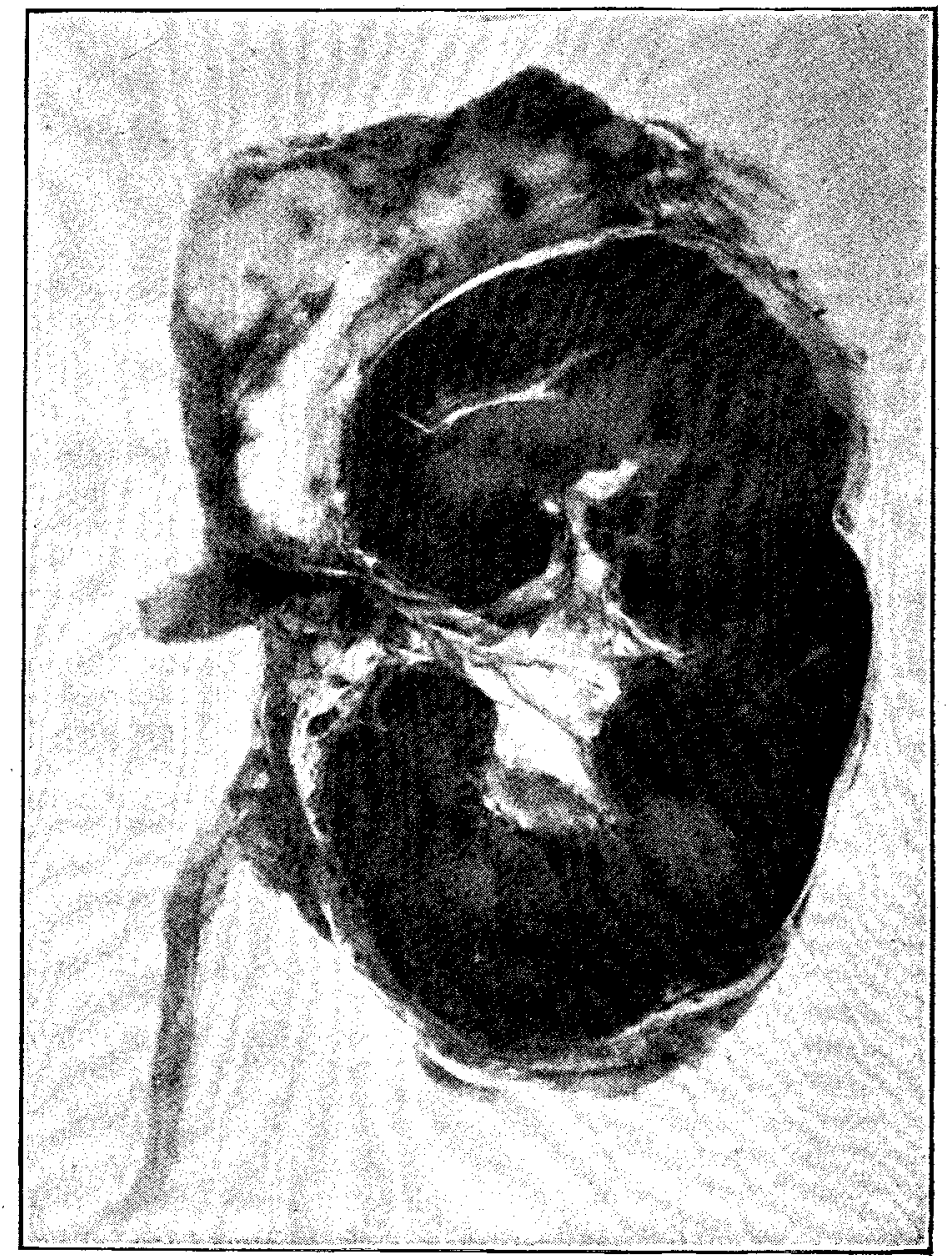

From a photograph of one kidney and suprarenal gland showing the advancen statre of the tibro-caseous change. The othe was similarly affectet. (Photograph by Miss Katherine Wortham.

The suprarenal glands were fibro-caseous, almost throughout, merely a narrow maroin of healthy gland tissue being discernible, and this only in a few areas (see figure). The fibrosis had spread into the adjoining posterior abdominal parietes, and must have involved the sympathetic ganglia, though these were not recognised. Caseous glands were found in the portal fissure and two caseous foci in the lowest lobes of the lungs, near the roots, probably representing glands also. Microscopically the tuberculous nature of the process was apparent. Many large giant cell systems and tubercle bacilli were seen. There was very considerable overgrowth of the lymphatic structures. The thymus, tonsils, lymphatic patches of the tongue and intestine, and the mesenteric glands were all hpperplastic, as in status lymphaticus. The spleen was considerably enlarged, reaching well down into the abdomen almost to the umbilicus, and weighing $5 \mathrm{oz}$ The pancreas, thyroid, thymus, spleen, and pituitary body 
were examined microscopically, but showed no abnormal change in their structure.

An especially interesting feature was the small size of the heart, which weighed only $3 \mathrm{oz}$. Its smallness attracted attention immediately after removal of the sternum and ribs, and it resembled in size more the heart of a child of two or three years old. This is only what is to be expected, considering the low degree of blood pressure which the boy must have had for some considerable time. It can, I think, properly be regarded as a true hypoplasia due to the little work which the heart was called upon to perform. In adults atrophy of the heart has often been described, but I have not encountered a description of cardiac hypoplasia in Addison's disease in children.

Queen Anne-street, W.

\section{POLYCYSTIC DISEASE OF KIDNEYS \\ REMARKABLE PERSISTENCE OF FUNC'TIONS IN TWO CASES IN ADULTS.}

BY H. RISCHBIETH, M.A., M.D., B.O. CANTAB., F.R.C.S. ENG.,

\section{AND}

C. P. C. De Crespigny, M.D., B.S. Melb., PATHOLOGIST, ADELAIDE HOSPITAL, SOUTH AUSTRAIIA.

THE two following cases of polycystic disease of the kidneys appear to be of sufficient interest to warrant recording. They offer contrasts in their clinical histories, morbid anatomy, modes of exitus, and it might be suspected in their mode of origin. The clinical histories of these cases were furnished by Professor A. Watson, of the University of Adelaide, by whom their publication was suggested.

In the first case the patient, a male, attained the age of 26 years without a symptom. He then had an attack of intestinal obstruction of a subacute and partial kind, and on examination a tumour was revealed, which was at first thought by his medical attendant to be a tumour of the descending colon. The tumour was subsequently diagnosed as renal, and on operation proved to be a polycystic kidney, which was removed. The right kidney was also ascertained at operation to be polycystic. The patient remained in perfect health for six years with one polycystic kidney, had no symptoms suggestive of renal disease, was passed for life insurance, and died from an independent disorder-acute septic meningitis secondary to otitis media, and as far as his renal functions were concerned might have lived for many years more. He showed an associated defect in an abnormality of the heart, and it might be supposed that this case was "congenital " in origin.

The second case was admitted into the Adelaide Hospital at the age of 62 years suffering from acute colitis, from which he died, and both kidneys were found to be polycystic on post-mortem examination. There was a history of gout, with a first attack at the age of 30 years, and of beer drinking ; and at the age of 62 years there was some not inconsiderable arterial degeneration, with, however, but little ventricular hypertrophy; but there had never been any symptoms suggestive of renal disease. And this type of case, if any, might perhaps be considered to have been " acquired." No facts upon the point of family or hereditary relationships could be obtained in either case; for no relatives could be traced. The kidneys of these two cases are shown in the accompanying figures.

CASE 1.--The patient, a man aged 27 years, was sent to the Adelaide Hospital by his medical man at Port Pirie as suffering from tumour of the descending colon.

History.-Fourteen days previously the abdomen became distended and the patient was unable to pass anything by the bowel. After enemata he passed flatus and was somewhat relieved. No vomiting. On the third day of illness a lump was observed by the medical man in the left side below the ribs. It caused no pain, but was somewhat tender on palpation. The patient vomited once on the fourth day. The
bowels were not opened for the first seven days ; after this they were regular. The motions at first contained a little slime and blood. Appetite fair; no jaundice. He had never had any pain suggestive of renal colic, nor any trouble with his urine. This had never been noted to be blood-stained or to contain "gravel."

Previous illnesses. - Ruptured since 13 years of age; had always worn a truss. "Catarrh of bowels" four months previously. Left pleurisy two years previously. Slight traces of plumbism (had been working as a smelter for six months). No syphilis.

Physical examination on admission.-Temperature, $99 \cdot 3^{\circ} \mathbf{F}$; t tongue moist, furred ; weath offensive; pulse-rate 76 , of malium rolume and tension. On the bucal surface of the luwer lin, on the lett sile in the region where the incisor teeth caune into montact with it, there were several sloughy ulcer's these were paintul. The lip was in heart or lungs. In the left sile of the abdomen, immetidtely luelow the costal margin, a clistinct, smooth, hard, roumler, oflung tumnor could be felt, lying in the flank. The fingers conld be got below this fixed, dial not more appreciably on respiration, was detined clearly

FIG. 1.

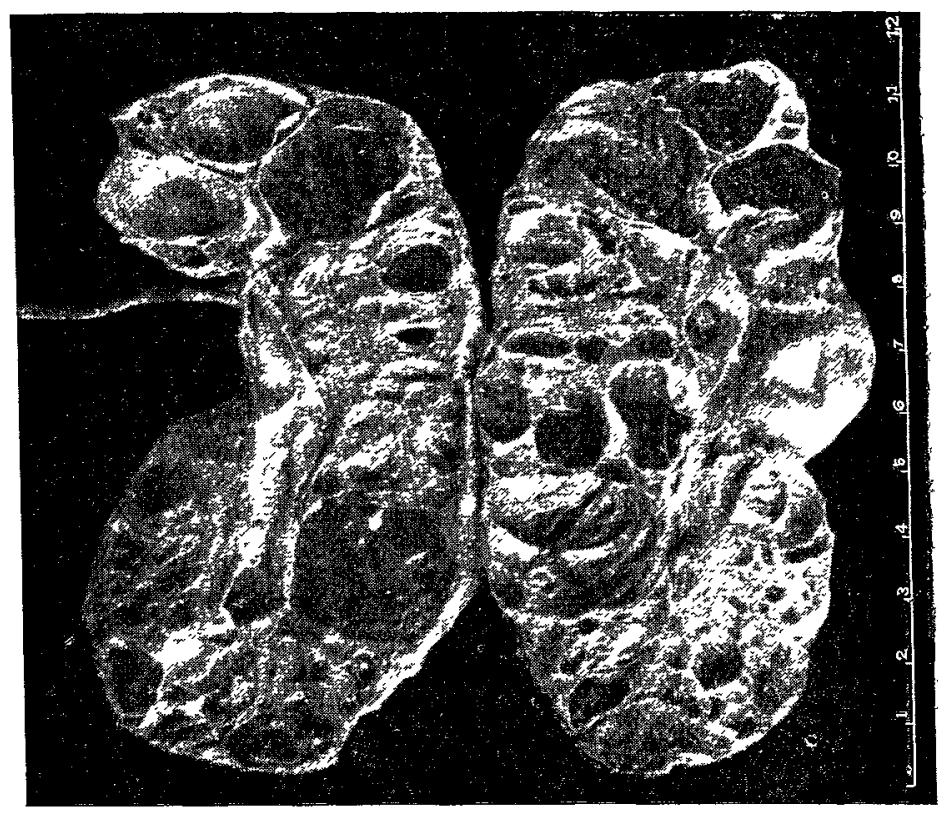

Case 1.-Right kidney polyejstic.

internally, and was slightly tender on palpation. Intestine could be made out anterior and internal to it. No abnormality could be detecter on the right side of the abdomen. Urineacid, 1008 , clear, pale; contained a faint trace of albumin, no sugar, and no deposit.

Two days after admission this tumour, the left kidney, was removed. It was completely cystic. Its maximum measurements were 12 by 6 by 3 in., and it weighed $5 \frac{1}{5} \mathrm{lb}$. A photograph, taken after nearly 6 by 3 in., and it weighed $5 \frac{1}{5} \mathrm{lb}$. A photograph, taken after nearly (Fig. 2.) On operation (Nov, 16th, 1905) the right kidney was also.

FIG. 2.

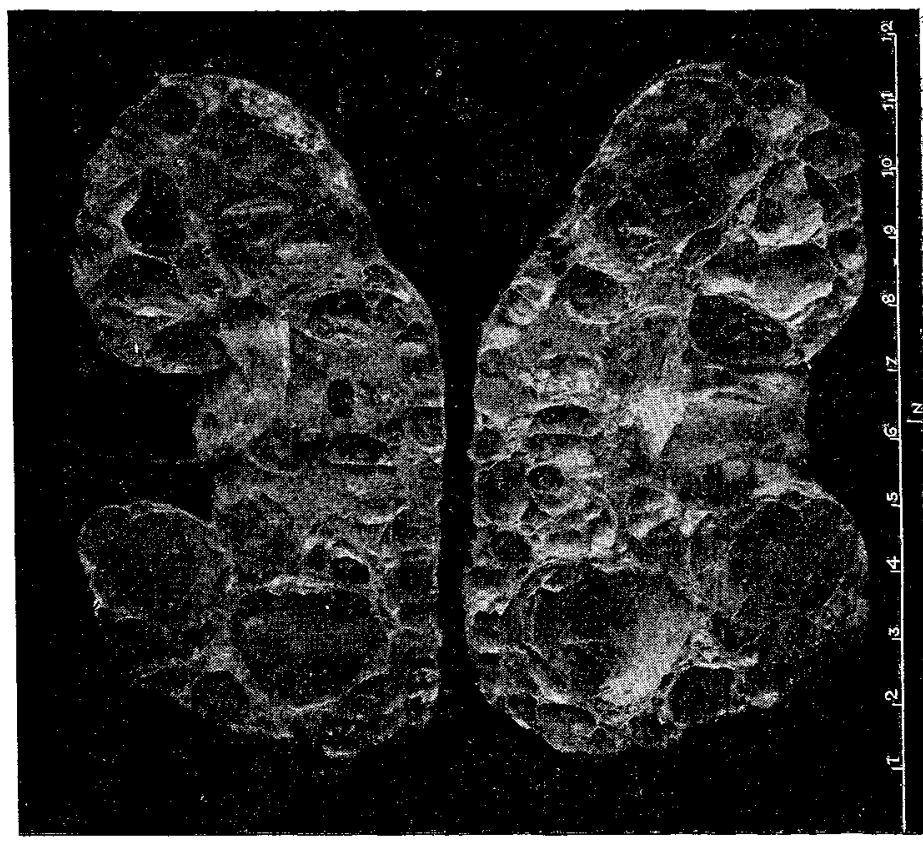

Case 1.-Left polycystic kidney.

recognised as much enlarged and polycystic. There were no essts in the liver or spleen, both of which were examined

The patient was shown at a meeting of the South Australian Branch of the British Medical Association 14 days after operdtion. and discharged to convalescent home 11 dass later. His weight, was then mi $\mathrm{et}$. increased (it had increased by $5 \mathrm{lb}$. in the last week). He was then passing on an average $97 \mathrm{Oz}$. of urine of low specitic gravity (1002) in the 24 hours. The patient had to be readmitted four days later by reason of an
attack of pneumonia, from which he eventually recovered. The urint 